\title{
DMF-t index level among school children based on parents socioeconomic status
}

\author{
Sujita Kurup Kutty Krishnan*, Avip Syaefullah*, Sri Susilawati* \\ *Department of Dental Public Health Faculty of Dentistry Universitas Padjadjaran, Indonesia
}

\begin{abstract}
\end{abstract}
Introduction: Malaysia is situated in the southeast region of the Asian continent. Oral health services became prominent in the 1970s as programs related to oral health care were gradually introduced in schools. Various national epidemiological surveys were done to assess the prevalence of dental caries among children in Malaysia. This study was aimed to find out the DMF-t index level among school children based on their parents' socioeconomic status by collecting consideration of education level and income of the fathers. Methods: This descriptive research with the survey technique was conducted at SJK (T) Klebang, Chemor, Perak, Malaysia. The DMF-t index of children in SJK (T) Klebang, Chemor, Perak was 0.2. Based on the questionnaire, the majority of fathers in Chemor, Perak were in the upper secondary education level with income ranging from RM 500 - RM 1000. Results: The Malaysian Oral Health Survey on 5 -years old children showed that the caries prevalence was $75.5 \%$. The mean of DMF-t was 5.57. An oral epidemiological study showed that $95.4 \%$ of 6 -years old children in Peninsular Malaysia had carious primary teeth. This figure dropped to $88.6 \%$ in 1988 , and by 1997 a further reduction to $80.6 \%$ was reported. DMF-t index consisted of the total number of Decayed, Missing and Filled teeth as well as a questionnaire on the socioeconomic background of the parents. Conclusion: The DMF-t Index of children in SJK (T) Klebang based on their father's socioeconomic status is within the range of "Very Low" based on the DMF-t Index Scale.

Keywords: Children, DMF-t index, income, socioeconomic factor.

\section{INTRODUCTION}

Malaysia is situated in South East Asia and abuts the neighbouring countries Indonesia, Singapore and Thailand. Malaysia is made up of two geographical wings, namely, Peninsular Malaysia and East Malaysia, which is composed of the states of Sabah and Sarawak. The beauty of Malaysia lies in its multiethnic culture. The ethnic breakdown is comprised of Malays $54.1 \%$, Chinese $25.4 \%$, Indians/Pakistani $7.5 \%$, Indigenous groups 11.7 and others $1.3 \%$. The historical record of dentistry in Malaysia can be traced back to
1869 when Cheong Chun Tin became the first practitioner to start a private practice. ${ }^{1}$

Various national epidemiological surveys were done to assess the prevalence of dental caries among children in Malaysia. The Malaysian Oral Health Survey on 5-years old children carried out in 2005 showed caries prevalence was $75.5 \%$. Mean DMF-T was 5.57. As a result, the health officials and the ministry of health needed a tool to plan for future health programs. Hence, surveys, census and as well as visits to community centres became a part of inculcating good oral health. A dental epidemiological study showed that $95.4 \%$

Corresponding author: Sri Susilawati, Department of Dental Public Health, Faculty of Dentistry Universitas Padjadjaran, Indonesia. Jalan Sekeloa Selatan I, Bandung, West Java, Indonesia, 40132; Phone: +6222-2504985/2532805 
of 6 years old children had carious primary teeth in Peninsular Malaysia. This figure dropped to $88.6 \%$ in 1988 , and by 1997 a further reduction to $80.6 \%$ was reported. Studies in Sarawak found 91.7\% caries prevalence in 6 years old children. In 1994 , this prevalence dropped to $88.2 \%$ while in 1997 prevalence was $79.6 \%{ }^{1}$

According to the National Oral Health Survey School Children ${ }^{2}$, it was proven that the oral health condition of the children related were still cause for concern. This is because, despite a reduction from $87.1 \%$ in the year 1995 to $76.2 \%$ in the year 2005, the mean df-t showed no similar decrease. Over ten years, the survey showed that it had only reduced from 5.8 in the year 1995 to 5.5 in the year 2005. In other words, there was only a slight decrease of 0.3 in a span of a decade.

This means governmental health facilities for oral health may not have been established until very late in Malaysia. Private practices were also scarce or almost unheard of till 1970 when care on dental health became a matter of concern for the Health Ministry as it was gearing towards a healthier and prosperous nation. Hence, caries control in children continued to be a big challenge. The School Dental Service is now the core business of public sector services. Expansion to cover almost $92 \%$ of primary and $60 \%$ of secondary school children has been mainly through the outreach strategy implemented in the early 1970s. Informally and affectionately known as 'flying squads', these mobile teams utilising portable equipment, ensured the expansion of services to all areas, including the rural areas. Mobile dental units increased about 31 -fold from 13 in 1970 to 407 in 2007. ${ }^{1}$ Despite its efforts the needed results were still not being met. It was then the Oral Health Division in the Ministry of Health $(\mathrm{MOH})$ devised goals and target areas to achieve.

The Malaysian government, therefore, set a target to achieve a developed nation status by the year 2020. It is from Vision 2020 that the National Oral Health Plan for the year 2010 was developed. There has been considerable improvement in the oral health status of Malaysians for the past 50 years. The main focus of the National Oral Health Plan is to improve the oral conditions of public health significance. ${ }^{1}$ Yet, out of 26 national oral health goals for 2010 , only 11 goals
(42\%) have achieved their targets. The majority of achievements are in the younger age groups for whom $\mathrm{MOH}$ bears responsibility. However, the oral health status of younger children who are not yet captive groups in the school system is still a continuing problem. ${ }^{2}$ Many efforts have been planned and carried out by orders from the Minister of Health in Malaysia to the Oral Health Division of $\mathrm{MOH}$ on the betterment of oral health conditions. This directive was then carried out with sufficient information of the program by mobilising the Government Dental Clinics in each area together with the cooperation of the Local Education Departments.

Based on the author's observations, the efforts consisted of bi-annual dental examinations at the primary and secondary schools, dentists and dental nurses together with the teachers of the schools brief its students on the toothbrushing techniques, and also talks on dietary issues such as nutrition and a suitable diet to maintain good oral health. However, the desired goals and targets of the Oral Health Division are still far from being met. The problem, therefore, lies not in its implementation and enforcement of the information on oral health. There may be other external factors which can affect its application on a mass scale. Such issues which play a part in making an agenda or plan successful can include the socioeconomic factors within a community, even minute detail within families.

Varenne et al. ${ }^{3}$ have stated that the prevalence of dental caries is related to socioeconomic factors in developing countries. Socioeconomic status is determined by these factors; education, job, salary and also living place as it is closely related to maintaining good oral condition. ${ }^{4}$ Therefore, it comes to the writer's interest to see the level of DMF-t index of children based on their parents' income and level of education within the population in Chemor, Perak.

The rationale for choosing this school was because it is situated in Chemor, a place to the northern part of the Kinta Valley, which is a dominantly densely populated region in the state of Perak. Chemor is also the house of light industry training and manufacturing. Therefore, it is adequate to say that it represents a socioeconomic status of its citizen ranging from the lower socioeconomic group to the higher 
socioeconomic group. The purpose of this research was to find out information about the level of DMF-t index among school children at Sekolah Jenis Kebangsaan (Tamil) Klebang, Chemor, Perak (SJK (T) Klebang, Chemor, Perak) based on their parents' socioeconomic status which was reflected by the level of father's education and income.

\section{METHODS}

Type of research was descriptive research using survey technique which consisted of clinical examination and questionnaire filling. The data consisted of DMFT index, as well as questionnaire the background of the children and parents' socioeconomic status.

The research population was the children in SJK (T) Sekolah Jenis Kebangsaan (Tamil) Klebang, Chemor, Perak. Some of the criteria for selection were children who were between the ages of $8-12$ years at the time of the research was conducted which was in April - May 2012, children without any systemic disorders, children who were not members of the same family (e.g. siblings), and children referring to both boys and girls.

\section{RESULTS}

Univariate analysis was performed to provide a descriptive explanation of the sample under investigation based on the data and variable of the subject matter.

Table 1 describes the proportion of samples based on age and their percentages. It shows that 30 students of SJK (T) Klebang, Chemor (33.3\%) were aged 8 years old, 16 students $(17.8 \%)$ were of 9 years of age. Fifteen students $(16.7 \%)$ fall into the age of 10 years old and 17 students (18.9\%) were 11 years old. The remaining population of students with a total of $12(13.3 \%)$ were of 12 years of age.

The proportion of the number of decayed, missing and filling tooth are summarized in Table 2. The DMFT index of children in SJK (T) Klebang, Chemor, Perak, Malaysia were calculated as follows: (Total value of DMF )/ (Total number of people examined). Based on the formula used to calculate the DMFT value in a population, the DMFT Index among the children at SJK (T) Klebang, Chemor, Perak, Malaysia was $18 / 90=$
Table 1. Percentage of students based on age

\begin{tabular}{cccc}
\hline No & Age & f & $\%$ \\
\hline 1 & 8 years & 30 & 33.3 \\
2 & 9 years & 16 & 17.8 \\
3 & 10 years & 15 & 16.7 \\
4 & 11 years & 17 & 18.9 \\
5 & 12 years & 12 & 13.3 \\
\hline & Total & 90 & 100.0 \\
\hline
\end{tabular}

Table 2. Number of decayed, missing and filling (DMF) tooth and DMFT index

\begin{tabular}{lllll}
\hline \multirow{2}{*}{ Name of school } & \multicolumn{5}{c}{ Total Number of } \\
\cline { 2 - 6 } & $\begin{array}{c}\text { Decayed } \\
(\mathrm{D})\end{array}$ & $\begin{array}{c}\text { Missing } \\
(\mathrm{M})\end{array}$ & $\begin{array}{c}\text { Filled } \\
(\mathrm{F})\end{array}$ & DMF - T \\
\hline $\begin{array}{l}\text { SJK (T) Klebang, } \\
\text { Chemor }\end{array}$ & 5 & 1 & 12 & 18 \\
\hline
\end{tabular}

Table 3. Educational background of fathers of children at SJK (T) Klebang, Chemor, Perak, Malaysia (\%)

\begin{tabular}{|c|c|c|c|}
\hline No & Fathers' level of education & $f$ & $\%$ \\
\hline 1 & UPSR (Primary education) & 4 & 4.4 \\
\hline 2 & PMR (Lower secondary education) & 17 & 18.9 \\
\hline 3 & $\begin{array}{l}\text { SPM/STPM (Upper secondary/Senior } \\
\text { high education/A - levels) }\end{array}$ & 52 & 57.8 \\
\hline \multirow[t]{2}{*}{4} & $\begin{array}{l}\text { Higher learning/Degree } \\
\text { (First/Graduate/Postgraduate) }\end{array}$ & 17 & 18.9 \\
\hline & Total & 90 & 100.0 \\
\hline
\end{tabular}

Table 4. Income of father's of children at SJK (T) Klebang, Chemor, Perak

\begin{tabular}{|c|c|c|c|}
\hline No & Father's income & $f$ & $\%$ \\
\hline 1 & RM 0 - RM 500 & 4 & 4.4 \\
\hline 2 & RM 500-RM 1000 & 39 & 43.3 \\
\hline 3 & RM 1000-RM 2500 & 27 & 30.0 \\
\hline 4 & RM 2500-RM 4000 & 11 & 12.2 \\
\hline 5 & RM 4000-RM 5000 & 5 & 5.6 \\
\hline \multirow[t]{2}{*}{6} & Above RM 5000 & 4 & 4.4 \\
\hline & & 90 & 100.0 \\
\hline
\end{tabular}

0.2. Therefore, the DMFT index among the school children at SJK (T) Klebang, Chemor was 0.2.

The data below was collected by survey technique consisting of questionnaires on the level of education as well as so-cioeconomic of the children and their parents.

Based on Table 3, there are only 4 students whose fathers $(4.4 \%)$ have had at least a primary education. Seventeen fathers $(18.9 \%)$ have had 
Table 5. DMFT index among school children based on father's level of education

\begin{tabular}{lcccccc}
\hline Father's level of education & Very low & Low & Average & High & Very high & Total \\
\hline UPSR (Primary education) & 4 & 0 & 0 & 0 & 0 & 4 \\
PMR (Lower secondary education) & 12 & 2 & 2 & 1 & 0 & 17 \\
SPM/STPM (Upper secondary/Senior high education/A - Levels) & 40 & 6 & 5 & 1 & 1 & 52 \\
Higher learning/Degree (First/Graduate/Postgraduate) & 15 & 0 & 2 & 0 & 0 & 17 \\
\hline Total & $\mathbf{7 1}$ & $\mathbf{8}$ & $\mathbf{8}$ & $\mathbf{2}$ & $\mathbf{1}$ & $\mathbf{9 0}$ \\
\hline
\end{tabular}

Table 6. DMFT index among school children based on father's income

\begin{tabular}{ccccccc}
\hline \multirow{2}{*}{ Father's Income (RM) } & \multicolumn{5}{c}{ DMF-T } & \multirow{2}{*}{ Total } \\
\cline { 2 - 6 } & Very low & Low & Average & High & Very high & \\
\hline $0-500$ & 4 & 0 & 0 & 0 & 0 & 4 \\
$500-1000$ & 25 & 6 & 5 & 2 & 1 & 39 \\
$1000-2500$ & 23 & 2 & 2 & 0 & 0 & 27 \\
$2500-4000$ & 11 & 0 & 0 & 0 & 0 & 11 \\
$4000-5000$ & 4 & 0 & 1 & 0 & 0 & 5 \\
More than 5000 & 4 & 0 & 0 & 0 & 0 & 4 \\
\hline Total & 71 & 8 & 8 & 2 & 1 & 90 \\
\hline
\end{tabular}

up to lower secondary school. Fifty-two fathers (57.8\%) have had upper secondary education/ pre-university education. Seventeen people (18.9\%) have a university education or in other words, have obtained a degree. This means the two levels of education, which are the lower secondary education and university education showed a similarity in percentages and population of fathers who have received this education. A majority, however, was seen in the upper secondary education which makes up about $57.8 \%$ of the total population of the respondents.

Table 4 shows that four people $(4.4 \%)$ earn between RM 0 - RM 500. About 39 people (43.3\%) earn between RM 500 - RM 1000. 27 fathers (30.0\%) earn about RM 1000 - RM 2500. Besides this, 11 fathers (12.2\%) earn RM 2500 - RM 4000. About five people $(5.6 \%)$ and four people $(4.4 \%)$ earn between the ranges of RM 4000 - RM 5000 and more than RM 6000 respectively.

Based on Table 5, which focuses on the DMFT index among school children based on their father's level of education, it was seen that the majority of children who're DMFT values are within the ranges of "Very Low". This is especially so for children whose father's level of education was up to upper secondary education. The table describes the majority of children have very low DMFT values.
Table 6 shows the DMFT level among school children at SJK (T) Klebang, Chemor, Perak based on their father's income. The majority of school children with "Very Low" index were found in the group of fathers who earn between RM 500 - RM 1000. Similarly, one child was found under the "Very High" DMFT value within the same group. This was different for fathers who earn more than RM 5000 a month for although there are four children under the category of "Very Low", none are found under the other categories.

\section{DISCUSSION}

From the data analysis, the DMFT index of the children was 0.2. However, when assessed from the DMFT scale, the data shows that the level of tooth destruction per child in Chemor was very low. This differences may be caused by inadequate dental health care and awareness of the parents of the lower socioeconomic area, which is a result of gaps in the level of education and income. The social background seems to relate to parents' ability to promote their children's education. For example, when parents teach regular toothbrushing, they also transmit ideals of goal-directed behaviour, enabling the children both to retain their dental health and to take care of their school duties. 
Tooth brushing may indicate a familial inclination to daily activities and to promote children's healthy development. ${ }^{5}$ As parental education about oral health increases, the likelihood of their children receiving preventive dental care also rises. Research also indicates that family coverage leads to improved access to care for children.

A study of low-income children showed that parents who received preventive dental care were five times more likely to take their children for a dental visit, compared with parents who received no dental care or visited the dentist only in an emergency. ${ }^{6}$ For the decayed tooth, it shows significant values for children from all levels of income. For missing tooth, the value was higher in children aged 10-years-old and above due to the fact of the presence of permanent dentition infected by caries. It is common for people with a low family income and those with a low level of education to have their teeth extracted on a more frequent basis. ${ }^{7}$

Tooth extraction is more extensively used by the poor, is the cheapest way to treat a damaged tooth. ${ }^{8}$ According to Nikias et al. ${ }^{9}$, those who were poor were less likely to seek preventive care. Most people prefer to have a tooth extracted instead of going for restorative treatment due to the high price of oral health services. In addition to dental disease, low levels of education and income and customs of oral hygiene might affect the decision about tooth extraction. ${ }^{7}$

For tooth-filling, it is higher for children of the lower ages as they had carious teeth but at a deciduous phase. Therefore, to retain teeth before the eruption of permanent teeth, this proved to be a method of care. A tooth filling is found more in educated people, whereas more missing tooth was found in less-educated people. ${ }^{9}$ Anderson and Newman ${ }^{10}$ stated that dental service utilization increased along with family income. Children from high-income family received early prevention treatment for their decayed tooth. It is easier to reach dental health services because there are many options in urban areas, and the fact that they have high purchasing power enables them to do so. ${ }^{11}$

According to Hoffman and Olsen ${ }^{12}$, income and waiting time influence the utilization of dental health services. Hoffman and Olsen also stated that for low-income people, the time spent waiting in the dental chair for care can be very costly, especially if the higher income group employs them. Aside from the level of income aspects, those having a high level of education will have good knowledge and will elicit good dental behaviour which will lead them to have better oral health. ${ }^{13}$

On the other hand, the majority of students in the school have been to the dentist to have their teeth treated. This shows that the level of awareness of the parents was higher, in fact, that there are many health facilities in their vicinity. Since children have been educated on dental health care and possessed some knowledge on the oral cavity, they proved to have an improved state of dental health. Thus, dental knowledge and attitudes were significantly affected by the level of education and family income. ${ }^{14}$

Education was associated with health behaviour after adjustment for other variables, suggesting that education is an essential factor involving attitudinal elements, which might improve adaptation and propensity to change behaviour. ${ }^{15}$ Significant difference in the level of education of the parents can be seen in Table 5 . As the level of education increases, the higher the degree of health care, as well as achieved dental care. This condition will further emerge as a healthy culture in the community. Covin ${ }^{16}$ stated that culture appears to play an independent part in health status. Income, on the other hand, plays a vital role in encouraging people towards obtaining better health care. Dental knowledge and attitudes are influenced by the level of education and family income. ${ }^{14}$ People with a higher purchasing power will have the ability to reach the optimum level in dental care.

In Table 4, about $43.3 \%$ of the fathers have a monthly income between the ranges of RM 500 - RM 1000. That means a majority of the students come from the medium up to the low-income families where their purchasing power is generally medium to low. This condition further influences their level of dental care directly.

Therefore, the socioeconomic status of parents substantially tend to affect the risk of dental caries in young children, even though they are covered by comprehensive public oral health programmes. ${ }^{17}$ 


\section{CONCLUSION}

DMFT index of children in SJK (T) Klebang, Chemor are within the "Very Low" category based on their father's level of education and income per month.

\section{REFERENCES}

1. Umer A, Umer A. Oral health care in Malaysia-A review. Pak Oral Dent J. 2011;31(1).

2. Oral Health Division Kementerian Kesihatan Malaysia. The National Oral Health Survey of Preschool Children 2005 (NOHPS 2005): Oral Health Status and Treatment Needs. Putrajaya: Oral Health Division Kementerian Kesihatan Malaysia; 2007.

3. Varenne B, Petersen PE, Ouattara S. Oral health behaviour of children and adults in urban and rural areas of Burkina Faso, Africa. Int Dent J. 2006;56(2):61-70.

4. Patrick DL, Lee RSY, Nucci M, Grembowski D, Jolles CZ, Milgrom P. Reducing oral health disparities: A focus on social and cultural determinants. BMC Oral Health. 2006;6(S1).

5. Koivusilta L, Honkala S, Honkala E, Rimpelä A. Toothbrushing as part of the adolescent lifestyle predicts education level. J Dent Res. 2003;82(5):361-6. DOI: $10.1177 / 154405910308200507$

6. Paradise J. Dental coverage and care for lowincome children: The role of medicaid and schip. Washington: The Kaiser Commission on Medicaid and the Uninsured; 2008.

7. Namal N, Can G, Vehid S, Koksal S, Kaypmaz A. Dental health status and risk factors for dental caries in adults in Istanbul, Turkey. East Mediterr Health J. 2008;14(1):110-8.

8. Stoyanova AP. Equity and Utilisation of Primary, Specialist and Dental Health Services in Spaini [dissertation]. Barcelona: Universitat de Barcelona; 2004.

9. Pintauli S, Hamada T. Menuju gigi dan mulut sehat. Medan: Universitas Sumatera Utara; 2008.

10. Andersen R, Newman JF. Societal and Individual Determinants of Medical Care Utilization in the United States. Milbank Q. 2005;83(4).

11. Kedeputian Pembangunan Manusia, Masyarakat dan Kebudayaan Direktorat Kesehatan dan Gizi Masyarakat. Penguatan Pelayanan Kesehatan Dasar di Puskesmas. Jakarta: Kementerian Perencanaan Pembangunan Nasional/Badan Perencanaan Pembangunan Nasional; 2007.

12. Cohen LA, Bonito AJ, Eicheldinger C, Manski RJ, Macek MD, Edwards RR, et al. Comparison of patient visits to emergency departments, physician offices, and dental offices for dental problems and injuries. J Public Health Dent. 2010;71(1):13-22.

13. Irani S, Meschi M, Goodarzi A. Influence of education on oro-dental knowledge among school hygiene instructors. J Dent Res Dent Clin Dent Prospects. 2009; 3(2): 56-59.

14. Al-Shalan TA. Factors Affecting Saudi Parents' Perception of their Childrens First Dental Visit. J Contemp Dent Pract. 2003;4(4):54-66.

15. Ylöstalo P, Ek E, Laitinen J, Knuuttila M. Optimism and life satisfaction as determinants for dental and general health behavior-oral health habits linked to cardiovascular risk factors. J Dent Res. 2003;82(3):194-9.

16. Salant T, Lauderdale DS. Measuring culture: a critical review of acculturation and health in Asian immigrant populations. Soc Sci Med. 2003;57(1):71-90.

17. Zhu L, Petersen PE, Wang H-Y, Bian J-Y, Zhang B-X. Oral health knowledge, attitudes and behaviour of adults in China. Int Dent $\mathrm{J}$. 2005;55(4):231-41. 